This is an Accepted Manuscript of an article published by CAMBRIDGE UNIVERSITY PRESS in SOCIAL POLICY AND SOCIETY on [date of publication], available online: http://wwww.tandfonline.com/[Article DOI].

Unpacking the Relationship between Parenting and Poverty: Theory, Evidence and Policy

Word count: 5,911

Authors:

Dr. Vincent La Placa (corresponding author)

Senior Lecturer, Public Health and Policy

University of Greenwich

Mary Seacole House

Southwood Site

Avery Hill Road

London

SE9 2UG

Email: v.laplaca@gre.ac.uk

02083318721

Judy Corlyon

Professional Partner

The Tavistock Institute of Human Relations (TIHR)

30 Tabernacle Street

London EC2 A4UE

Email: jcorlyon@ googlemail.com

07799388892 


\section{Unpacking the Relationship between Parenting and Poverty: Theory, Evidence}

and Policy

Policy discourses around child poverty and its causes and effects on families emerged in the 1990s, culminating in the Coalition Government's emphasis on the quality of couple relations in improving child outcomes and in reducing child poverty. This article reviews and updates the current evidence base around the relationship between parenting and poverty. Evidence suggests an intricate relationship between complex and mediating processes of, for instance, income, parental stress, disrupted parenting practices, and neighbourhoods and environments, as opposed to a simplistic causal relationship between poverty, parenting, and child outcomes. The article then proceeds to suggest responses to enhance the evidence and research. Lastly, it considers the implications for child poverty policy, arguing that current responses are too simplistic and do not sufficiently reflect the evidence base.

Key words: parents, poverty, dynamics, research, social policy.

\section{Introduction}

It was during the 1990s that policy discourses emerged in the UK in response to tackling child poverty and action was taken by the Labour Government to reduce it as part of a wider poverty reduction strategy (Edwards and Gillies, 2004; Tavistock Institute et al., 2014). The emphasis was largely, though not exclusively, on measuring child poverty in terms of fiscal and household income and raising levels of income through higher welfare benefits and inclusion in the labour market. Such 
policies were perceived to enhance parents' ability to nurture children, both emotionally and financially. Assistance with parenting in the form of parenting classes was also perceived as complementing the fiscal aspects of poverty reduction (Asmussen et al., 2007; Avis, 2007; Axford et al., 2012; Davis et al., 2012).

On assuming power in 2010, the Coalition Government commissioned an independent review on poverty and life-chances which considered the case for reforms to child poverty measures, particularly the inclusion of non-financial elements and of addressing the underlying roots of poverty. The resulting document (Field, 2010), and a subsequent report on early intervention, (Allen, 2011) concluded that focusing on reducing poverty by fiscal means was not the solution to determining whether children's potential could be realised in adult life. Consequently, an alternative strategy was required to reduce the chances of the cycle of deprivation by which poor children eventually became poor adults. As a result, the key focus is now on the strength and stability of adult relationships and their effects on child-wellbeing outcomes (Field, 2010; Allen, 2011). This marks the beginning of a significant shift in emphasis away from the parent-child relationship to the importance of the couple in family policy. A key element lies in supporting home environments, stemming from the belief that children who grow up in stable families with quality relationships stand the best chance of a positive future.

However, this same period has witnessed significant reductions in income for many families, particularly for those least well-off. Reforms to the welfare benefit system and pressure to take up employment, no matter how low-paid and insecure, bring increased financial and practical difficulties for many families. The housing benefit cap and the under-occupancy penalty ('bedroom tax') may mean some families have to move home, disrupting children's education and existing social and 
community networks (Gentleman, 2012). Furthermore, it has been argued that the shift to the strength and stability of adult relationships in securing positive child outcomes is merely an extension of neo-liberal ideology which emphasises the individuation of relationships and the moral responsibility of parents to provide effective parenting (Robson, 2010). For example, parenting classes accentuate the neo-liberal tenet that parents are primarily responsible for reducing achievement gaps and inter-generational disadvantage (Daly, 2011; Hartas, 2014). This approach sidelines socio-economic status and material poverty, ensuring parents have to live up to the standards of neo-liberal tenets (Gillies, 2005a; Daly, 2011; Reay, 2013) in an era of increasing structural inequalities (Hills et al., 2010).

Research points to the need to improve the circumstances of children living in poverty who experience significant disadvantages in terms of cognitive development, socio-emotional functioning and physical health problems (Newland et al., 2013). Living with financial hardship has profound effects for parents in terms of psychological distress, marital conflict and stress (Furstenberg et al., 1999; Ross and Roberts, 1999; Cawson et al., 2000; Pheonix and Husain, 2007). However, the current knowledge base around parenting, poverty and child outcomes is often grounded within ideas of 'parenting problems' (Katz et al., 2007a; Gillies, 2007), the implication being that parents who live in poverty display a deficit in parental abilities due to the increased difficulties which financial hardship brings. It is true that poor parents are more likely than more affluent ones to be confronted with a range of material and non-material disadvantages. These can include isolation, poor health, lack of access to jobs and services (Katz et al., 2007b; La Placa and Corlyon, 2014a), and relationship difficulties that disrupt ability to parent adequately. However, this stance inevitably misses the complexity and multi-dimensional 
construction and experience of poverty (Smith and Middleton, 2007; Boyden et al., 2012). The disadvantages outlined above may act as linking independent predictors, but are also likely to converge and be constituted in and through interactive processes that mediate the ability to parent, producing other processes and outcomes and to proceed beyond issues around parenting 'problems'. This makes it all the more challenging in disaggregating the effects of parenting on child outcomes and poverty.

Understanding the complex construction and experience of poverty is central to theoretical debates around the roles of structure and agency among social policy makers and researchers (Giddens, 1984; Alcock, 2006). The structural approach accentuates the primacy of structural social circumstances and wider determinants in influencing life-courses, life-chances, and economic outcomes, such as economic growth, neighbourhood context, and social policies. The agency approach emphasises the central importance of individuals' abilities to actively and discursively construct and reframe their lives, practices and circumstances through choice and agency. As a result, a school of thought has emerged that combines both structure and personal agency (Giddens, 1984; La Placa et al., 2014). Social environment and structure is both the medium and the outcome of social action and individuals negotiate through this reflexively, producing change over time and space.

In this article, poverty is conceptualised as dynamic and contingent (Gordon and Nandy, 2012) and produced and experienced through an array of intricate interacting and intermediate factors, including families, parenting, and neighbourhood and environment. It proceeds beyond unilinear frameworks of absolute and relative poverty (Gordon, 1998; Lister, 2010) to a multi-dimensional approach that focuses upon how deprivation, social practices and outcomes emerge through and by structure and agency (Alcock, 2006). Linked to this is the emergence 
of 'poverty dynamics' (Smith and Middleton, 2007) whereby poverty is conceptualised as a complex process, meaning that there are different forms and experiences of and pathways into poverty.

The article refers to parents as individuals who provide significant care for children on the physical, emotional and social level (nurturance and socialisation), including grandparents and other relatives and adults not biologically related to the children (Katz et al., 2007a). This is to maximise inclusivity and ensure the review covers a diverse range of families and contexts. Parenting is conceptualised holistically (Bronfenbrenner, 1989; Belsky and Vondra, 1989) and constructed within influences from cultural contexts, communities and characteristics of parents. These contexts often influence parenting styles and types, usually defined in terms of how responsive they are to or demanding of their children (Baumrind, 1991).

The major themes of recent research on child poverty have primarily focused upon objective measurements and indicators of poverty, standard child outcomes, and the mechanisms through which cycles of poverty can be severed through material means i.e. higher incomes (Ermisch et al., 2001; Yaqub, 2002; Katz et al., 2007a). They have rarely considered other complexities such as the role of parents and parenting processes in the relationship between poverty and child outcomes. This article reviews literature addressing the potential relationship between parenting and poverty, the key issue being the extent to which poverty itself affects parenting or whether other characteristics and contexts of parents who live in poverty, such as family relationships or neighbourhoods, have an impact. Intrinsic to this is the extent to which poverty can exert separate effects which are distinct from other risk factors encountered by materially deprived parents, and whether parenting itself can operate 
as a protective buffer to the deleterious effects of poverty. It then proceeds to explore the implications for further research and policies around child poverty.

\section{Methods}

Evidence was generated through a narrative review which uses various sources from which conclusions are produced into holistic interpretations, based on reviewers' own experiences of existing theories and models (Popay and Mallinson, 2013). It provides an interpretative synthesis using findings from various sources. Reviewers produced exhaustive inclusion criteria to generate the most effective evidence in providing information about potential links between parenting and poverty. The primary inclusion criteria were that research should be primarily from a credible academic perspective (i.e. not anecdotal or unpublished evidence) and that literature focused primarily on links and relations between parenting and poverty. However, it appears that much of the literature often focuses primarily on material poverty and child outcomes, with parenting conceived as a secondary variable. It pays little attention to parenting's potential role in mediating between different outcomes.

To increase the range of evidence no cut-off date for articles was established. Evidence was also included if it originated from countries with similar social, economic and demographic characteristics to the UK such as the USA, Canada, and members of the European Union. Evidence was excluded if it originated from other countries different from the above or was overly focused upon outcomes with no regard to parents. As a result, relevant key search terms were drawn up and employed to guide the selection of relevant evidence. For instance, 'parenting practices' and 'poverty' were combined as search terms. Another example was the combination of 
the search terms, 'parental practices' and 'neighbourhoods'. The search engines International Bibliography of the Social Sciences, SwetsWise and JSTOR were used to select sources. In total, 171 sources were identified initially through reference to the title of the relevant article/document. This was further reduced to 113 through extensive reference to the abstract/introduction to ensure rigorous adherence to the inclusion criteria and relevance to an exploratory narrative review. All 113 sources are cited in this article.

The review is skewed towards studies from the UK and US from where most literature originates. Research from mainland Europe is still sparse, as it was in past reviews (e.g. Katz et al., 2007a). However, this is not to gloss over the fact that child poverty has a global dimension (Alcock, 2006) and that international evidence is as valid to UK policy. The review consists of quantitative and qualitative sources. This enables a focus upon broad structural determinants and quantitatively measured outcomes, but also sheds light on qualitative and interactive processes. Data sources were critically appraised for relevance, usefulness and validity of findings (Hill and Spittlehouse, 2003). Key themes were generated through the application of a thematic analyses and synthesis of data approach (Gibbs, 2007). Similar concepts and findings were summarised under thematic headings and tabulated to enable identification of prominent themes after rigorous reading and coding of data. As a result, themes could be deconstructed to enable identification of the sub-themes and processes which comprised the overall theme. The advantage of a narrative review was its ability to provide a plurality of diverse research and information, bounded into a comprehensive question and research topic, but one which enabled a reflexive position to be taken when reviewing literature. However, it is important to acknowledge that the evidence base often takes child outcomes as the primary focus, with limited focus upon process 
and pathways. It is also frequently predicated upon 'snapshots' of parents in poverty, often comparing them to affluent parents.

\section{Parenting and poverty: the evidence}

The article posits that five discernible themes emerge that capture the literature: the culture of poverty; stress; poor environments and neighbourhoods; parental resilience; and parental involvement with education. Evidence tends not to claim that income differences are the absolute determinant of parenting ability; but neither does it posit that economic hardship and income have no bearing upon parenting. Neither are emergent themes mutually exclusive, but are often a combination of structural and individual contexts.

\section{The culture of poverty}

The culture of poverty theme premises that the persistence of poverty is the product of a culture, in which poor people have their own distinctive patterns of attitudes, behaviour and priorities of values which are transmitted between generations through socialisation. This leads to successive generations experiencing poverty and disadvantage. As a result, fiscal measures are not viewed as the answer to lifting the poor out of poverty: the solution is to interrupt the cycle of transmitting negative values by changing attitudes, lifestyles, behavioural drivers and parenting styles of materially poor parents (Welshman, 2007). 
Yaqub (2002) argued that the persistence of poverty across several countries is significantly down to inter-generational transmission of parental values around low expectations of work and education. However, whilst socio-economic background strongly influenced behaviour, child outcomes were not solely determined by them. Through resilience and 'plasticity' (capacity to reverse psychological and social damage) parents could counterbalance the effects of poverty at almost any time through the life-course. Family outcomes were also affected by childhood poverty, family disruption, contact with police, educational test scores, fathers' interest in schooling and insecure attachment bonds between parents and children due to the stress of coping with poverty (Hobcraft, 1998; Chen and Caplan, 2001; Moulin et al., 2014). Lexmond and Reeves (2009) argued that parents' resilience and confidence in themselves to transmit 'character capabilities' to their children mediated the effects of material poverty. However, in the absence of studies of the parenting styles of individuals who experienced very different socio-economic conditions and upbringings from those of their own children, it remains unclear as to what extent intergenerational similarities are factors of learned behaviour, compared with responses to the parenting environment. Archer et al. (2012) pointed out that family 'habitus' and cultural capital interplay with economic capital and can make aspirations more 'thinkable' for middle-class children than for working-class children.

In the light of this, the review uncovered more consistent findings in relation to poverty and family structure, especially lone parenthood (Marsh and McKay, 1994; Berthoud et al., 2004). O’Neill (2002), Curtis et al. (2004) and Holmes and Kiernan (2010) posited that lone parenthood caused poverty and, as a result, produced negative physical and behavioural child outcomes (when income and neighbourhood were controlled for) compared with two-parent families, where incomes were larger. 
However, Rigg and Sefton (2004) point out those even two-parent families can experience a temporary decline in income, particularly at the birth of a new child which often reduced opportunities for one of the parents to take up paid employment. Lundberg et al. (1997) focused on routes of income distribution within families, demonstrating that when mothers were the main earners more money was spent on children than where fathers were. Regardless of evidence, Gillies (2008) and Hartas (2012) posited that the culture of poverty thesis often negated situated contexts of deprivation, promoting false neo-liberal beliefs that responsible parenting, rather than collective policies to reduce poverty, is essential to social inclusion.

\section{Stress}

The second theme suggested that materially disadvantaged parents experience more stress than affluent ones and viewed stress as a significant intermediate process in the link between parenting and poverty (Kumar, 1993; Oakley et al. 1994; Spencer, 1996; Bradbury, 2003; Turner, 2006; About Families, 2012). Evidence often perceived stress as the various processes that precipitate negative psychological and physiological reactions originating from attempts to adapt to the demands of parenthood (Elder, et al., 1985; Larzelere and Patterson, 1990; Harris and Marmer; 1996; Ghate and Hazel, 2002; Sastry, 2015). This causes parents to be more depressed, agitated and/or angry. As a result, they tend to display more authoritarian and/or inconsistent parenting patterns, impacting negatively on child outcomes. Much of the evidence bears out this chain of events and suggests stress is at least partly responsible for differential outcomes in poor families (Waylen and Stewart-Brown, 2009). Moore and Vandivere (2000) ascertained that poor, stressed parents are less 
likely to provide optimal home circumstances and more likely to display coercive and harsh disciplinary methods. Evidence has also highlighted the negative effects of financially induced stress on health and wellbeing and, more specifically, on birthweight, diet and life-chances (Jefferis et al., 2002).

Conger et al. (1995) found that adolescents whose families moved from affluence into poverty displayed negative emotional wellbeing and behaviour. This was mainly the result of disruptions in parenting rather than material poverty. The disruption was caused by distress, depression and deterioration in marital relations. Russell et al. (2008) found that depression and 'despair', associated with poverty and stress, were perceived to impair parenting and to enhance self-doubt about parenting ability. Throughout the literature, one notable aspect of stress related to the gender of the parent, and especially, the impact of depression on mothers. Generally, the review suggested that lower income mothers are more at risk of depression than higher income ones. Contributing factors to maternal depression were, typically, absence of a strong relationship with significant others, number of children, and a disrupted relationship with their own mother.

Meltzer et al. (2000) found that children from unemployed and/or unskilled working-class backgrounds in the UK were three times as likely to develop mental disorders as those from professional backgrounds. Furthermore, the likelihood of children experiencing mental health difficulties was also closely linked with their parents' negative mental health. This demonstrated that children with mental health problems and 'difficult' children were closely associated with stressed parents. Evidence also suggested that there was no straightforward relationship between poverty and emotional abuse, inadequate parental supervision or harsh discipline; neither was there adequate evidence proposing that 'parenting deficit' is related to 
poverty or level of income in itself (McSherry, 2004). Rather, the enhanced risk predictors associated with poverty and a stressful environment increased the likelihood of use of physical/authoritarian discipline. Nevertheless, access to a higher income has a protective effect and reduces the stress associated with material poverty.

Whilst the weight of the evidence favours the stress/disrupted parenting/poor outcomes argument as the principal device of the parenting/poverty link, there is no universal agreement around this. Mayer's (1997) analyses of cohorts in the US found that parents' incomes had only a modest impact on stress, and that stress exerted a minimal influence upon child outcomes such as educational attainment. Rather, it was poorer parents' failure to take advantage of economic and educational opportunities that affected child outcomes and prevented effective parenting (regardless of income levels). However, this research failed to acknowledge that parents are often excluded from mainstream economic opportunities by structural inequalities and low social capital as much as by personal failings (Katz et al., 2007a).

Nevertheless, debates around the effects of income, stress, and poverty will continue to inform debates around the impact of employment and welfare-to-work schemes in lifting incomes, reducing stress, and producing positive outcomes. Research does not universally endorse the argument that increased parental income through labour market participation or higher welfare benefits directly improves parenting capacities or generates more positive child outcomes and reduction in stress and/or anxiety (Epps and Huston, 2007; Ridge, 2009; Alakeson, 2012; Levitas, 2012). What is more, the review suggested that parenting style and practice are themselves historically and relatively stable constructs (Katz et al., 2007a). Modification may occur in response to crises such as loss of income, but not so readily to more subtle changes in family circumstances such as a child's under-achievement at school. 
Changes to income are not invariably combined with changes in consumption or lifestyle and behaviour. Income reduction can be counterbalanced by drawing upon savings, and increases in income may be adversely affected by the requirement to pay off debt.

Future research needs to direct attention to the overall effects on families of income changes and disaggregate the differential effects on different groups of parents with various parenting styles and practices. Another gap in the research on stress is the effect of children upon parents. Children can be either stressors or buffers to stress and adversity, depending on their health status, behaviour, and needs (Epps and Huston, 2007; O’Connor and Scott, 2007; Sastry, 2015).

\section{Poor environments and neighbourhoods}

The poor environment and neighbourhood theme posited that parents' characteristics and parenting styles are significantly influenced by the neighbourhood and environment (Pinderhughes et al., 2001; Caughy et al., 2003; Leventhal and BrooksGunn, 2003; Barnes, 2004; Gutman et al., 2005; Van Ham et al., 2014). Neighbourhoods which comprise similar levels of material deprivation but different levels of social capital or 'social disorganisation' will produce different types of parents, with varying child outcomes. 
Jencks and Mayer (1990) posited four theoretical models through which neighbourhoods may impact upon parenting. The epidemic or contagion theory suggested behaviour is learned or emulated in that the presence of anti-social young people can spread problem behaviours such as substance abuse or delinquency. Collective socialisation emphasised role models, local social norms, alienation, acceptance of anti-social behaviour and instability in the community. Parents may be socialised into patterns of inappropriate parenting as a result. Competition theory highlighted competition between families for social and material resources available in the community and the resulting challenges from the inability to mobilise them. Competition enhances the likelihood of an underclass with access to the least resources. Relative deprivation theory advocated that individuals judge their social position in comparison to neighbours. This can result in exclusion and demoralisation if other families appear more affluent, harming community cohesion.

The contagion and collective socialisation explanations assumed that socially mixed communities may enhance child development, leading to better health and behaviour outcomes (Leventhal and Brooks-Gunn, 2003). Competition and relative deprivation explanations asserted that competition from advantaged neighbours can be deleterious to children in poverty. Research, particularly in the US, has discovered that higher rates of child maltreatment are more common in areas of significant exposure to risk factors at the individual and household levels resulting from inequality in the neighbourhood and/or community (Fauth et al., 2007). Contrasting research, however, demonstrated that direct neighbourhood predictors had only a marginal effect on child outcomes. Rather, parenting styles and the perceptions of poor neighbourhoods are more significant, and can often mitigate neighbourhood and environmental effects (Ghate and Hazel, 2002). Parents' own backgrounds, children's 
personalities and family relationships remain the most significant predictors, even when movement between deprived and mixed communities and depth and duration of poverty is accounted for (Sanbonmatsu et al., 2006). Being a lone parent (particularly a lone mother) can reduce income and produce negative emotional and behavioural child outcomes, regardless of the economic consequences of the locality, as can having a large family (Dyson et al., 2009) and lacking affordable childcare. The quality of the neighbourhood affects children's educational attainment less than the home environment and parental interest in children's education does (Feinstein et al., 2004), with the latter being related to class and income, material deprivation, maternal psycho-social health and lone parent status rather than the neighbourhood (Epps and Huston, 2007; Gutman et al., 2009; Friedrichs et al., 2013).

Most parents in poor neighbourhoods can also parent as effectively as families in less deprived areas (Ghate and Hazel, 2002). Social support and integration within the community and strategies to ensure that family resources are utilised economically and distributed fairly can act as buffers against stress and potentially harsh discipline (Moran et al., 2004; Attree, 2005). Although such 'snapshot' studies do not suggest a causal association between parenting and poverty outcomes, they do indicate that parents living in poor neighbourhoods are more likely than those in less deprived areas to face stressors and psychological constraints, resulting in higher levels of anxiety and depression. Neighbourhoods that encourage educational development, take-up of social capital, and access to high quality services improve the experiences of poorer, stressed parents. 


\section{Parental resilience}

Whilst an array of parenting styles is present across all socio-economic groups, the review indicated that there was no causal relationship between income and parenting style (e.g. Peters et al., 2008; Moulin et al., 2014). Whilst child maltreatment and lack of parenting capacity was predominant in lower income parents, the review uncovered resilience in parenting even in adverse circumstances. Parental capacity is located within wider contexts of communities, networks and children's characteristics, which mediate between material incomes and affect parental resources such as resilience and strategies to cope with and manage adversity (Belsky, 1984; Parke and Buriel, 1998; McDonald et al., 2012). Various studies (e.g. Middleton et al., 1997; Ghate and Hazel, 2002) found that parents often sacrificed food and resources so that their children had more. Lindblad-Goldberg (1989) and Fram (2003) reported that material poverty was mitigated through development of coping mechanisms such as positive family concepts around loyalty, the home, adequate communication, and stressreducing access to neighbourhood, family and friendship networks. Parents were then less likely to exert harsh discipline and more likely to gain more adequate access to services and employment, despite material deprivation.

\section{Parental involvement with education}

One other specific aspect that recurred in the literature was that of class, family economic resources and parents' abilities to raise children's educational attainment through involvement in their education. (Ashworth et al., 2001; Desforges and Abouchaar, 2003; Blanden and Gregg, 2004; Feinstein et al., 2004; Sullivan et al., 2010; Kiernan and Mensah, 2011; Holmes and Kiernan, 2013; Park and Holloway, 
2013). Dahl and Lochner (2005) and Cooper and Stewart (2013) argued that past and current material income constitutes the most significant variable in enhancing children's scholastic achievement, concluding that enhanced income would effectively raise attainment and enhance parenting practices. Feinstein's (2003) longitudinal study of British children also argued that children from higher socioeconomic backgrounds performed better overall in school, even tending to improve educational scores when they had initially scored less well than children from lesser backgrounds. Type of schooling had no overall effect. Nevertheless, there was evidence to suggest that income and deprivation can be partially influenced by factors within the home environment such as parental inclusion in learning and schools in the form of library visits, and parental emphasis upon success and aspiration, as well as their own educational qualifications and quality of learning environment (McCulloch and Joshi, 2001; Desforges and Abouchaar, 2003; Hartas, 2011; O’Connor and Scott, 2007; Siraj-Blatchford, 2010; Gregg and Washbrook, 2011). Borgonovi and Montt (2012) contended that parental involvement should not be construed similarly across all cultures and countries, and that specific forms of involvement assist children's cognitive and non-cognitive abilities at different points.

Otter's (2013) longitudinal survey of a Swedish cohort born in 1953 discovered that parents' beliefs around children's educational aspirations and involvement significantly enhanced educational attainment in families with fewer economic resources, challenging the idea that poorer parents were not involved. However, it was also the case that involvement was higher in families with higher levels of income and social capital. Otter (2013) warns against the idea that responsibility for children's educational is only with parents as opposed to economic resources. Similarly, Gillies (2008) found that working-class parents with 
academically struggling children often assisted them to cope through accentuating non-academic characteristics and practices. Whilst parents were keen to stress the benefits of academic achievement, they played down the significance of low achievement. Gillies (2005a; 2005b) and Hartas (2012) argued that class remained important in focusing upon the role of parents in facilitating education and social improvement, particularly working-class parents, who often face considerable adversity. They contend that lower working-class achievement was often the result of material poverty rather than lack of parental resourcefulness and aspiration. This is coloured by tendencies to apply middle class standards to interpret parental resourcefulness in contexts where material poverty renders it harder to live up to them.

\section{Current evidence}

Current evidence indicates an intricate relationship between poverty, parental stress, inclusion in children's education, and neighbourhoods and environments. There appears no simplistic causal relationship between poverty, parenting, and child outcomes. Different people respond differently to adversity. Elements of length and depth of poverty, family structure, neighbourhood, and social support interact with parents' behavioural drivers which mediate and affect responses to adversity. Poverty exerts a significant influence in that it engenders some parents to be more stressed, depressed or agitated, which disrupts parenting. Disrupted parenting, rather than poverty, can constitute the key determinant in affecting child outcomes. Nevertheless, this relationship is not straightforward, given the parental resilience uncovered in the review. Furthermore, the direction of the relationship currently remains unresolved. It is possible that parents who have a history of, or are temperamentally pre-disposed 
towards stress, are more likely to become stressed and consequently less likely to hold down employment (Katz et al., 2007a).

There are various processes and outcomes inherent in relationships between poverty and parenting. Socially excluded and low-income parents may face depleted levels of social capital and parenting ability for various reasons. Evidence suggests that once women have children they often find themselves taking lower skilled and/or lower paid jobs due to the high costs of childcare, inflexible jobs, and the lack of high-quality part-time work (Alakeson, 2012). As a result, individuals who previously parented adequately may fail to do so when faced with new challenges. Clearly, this can disrupt a family's income, relationships and parenting capacities.

\section{Further research}

The current evidence base requires responses that focus upon the complexity and dynamic contingency of poverty as produced and modified on the individual and structural levels. Evidence is often predicated upon objectively measured child outcomes, viewing parenting as an isolated variable working in conjunction between other 'external' variables such as poverty or neighbourhood disorganisation. However, to grasp the complex inter-relations between the two, we advocate the need for more poverty research that will capture the dynamic and multiple processes and experiences within them (Smith and Middleton, 2007; Lister, 2010).

As Boyden et al. (2012) assert, poverty is as much a process that is transmitted through the language of human, financial, social and cultural 'capital' as it is through structural social circumstances and wider determinants. Rather than simply asking 
how much poverty affects parenting, research and subsequent policies need to shift to more subtle questions around how do changing levels of income make a difference to parenting? What are the particular features of poverty and its specific mechanisms by which it affects different aspects of parenting, such as discipline and involvement in education? How is poverty affected through different types of parenting and neighbourhoods? Focus should shift to families and communities as key coconstructors in the process, rather than intermediate variables in the production of measurable child outcomes, as is the case with much of the evidence. For example, how do parents potentially change parenting practices and styles in relation to changes in household income or children's ages? Do these changes have short or long-term effects on children? How do parents actively draw upon the individual and structural rules and resources within the community (Giddens, 1984) and incorporate them into parenting styles and practices?

As a result, more longitudinal research to complement existing studies (e.g. Feinstein, 2003; Borgonovi and Montt, 2012; Otter, 2013) is required. This should be grounded within poverty dynamics research that pursue parents as they manoeuvre in and out of poverty, assessing changes in parenting style and experience over time. This might focus upon children maturing (O'Connor and Scott, 2007) and subsequent effects on parents of movement between different neighbourhoods, increases or depletion in social capital, and perceived support and control over their situation (regardless of affluent neighbours). It would track changes in parenting styles in response to different situations and dynamic changes in children's behaviour and provide for more detailed context. Attention should be directed to parents who shift in and out of poverty and those who remain there, the emergence and interpretation of risk factors, and the pathways to particular child outcomes. 
There is also a need to focus on comparisons between the parenting of people in poverty and those who are not, but face similar personal and environmental stressors. There is space for more evidence on poverty's effects on parenting style as differentiated from those on parenting practices and beliefs. These three dimensions come into play independently but it is not apparent how poverty interacts independently with them. More evidence and research should also be directed towards comparisons of differential impacts on parenting of anti-poverty strategies, particularly ones that assist parents into work or those that raise income through welfare benefits (Levitas, 2012).

\section{Policies}

An enhanced and detailed evidence base is increasingly important to inform current social policies around child poverty more effectively in the light of the Coalition Government's emphasis upon the strength and stability of couple relationships and effects on child-wellbeing outcomes (Field, 2010; Allen, 2011). Based on the evidence, it is too simplistic an approach. The current evidence suggests that quality of adult and couple relationships cannot be conceptualised as isolated and developmental variables (Gillies, 2013), separate from other structural and individual processes such as behaviour, income and environment (Gillies, 2011). Neither is there sound evidence that the strength and stability of a couple relationship alone produces 'effective' parenting, as if the former is an inevitable pre-condition for the latter, or that it will reduce child poverty. In fact, Jensen and Taylor (2012) argue that such concepts are themselves austerity discourses that accentuate neo-liberal concepts of personal morality and responsibility, whilst negating poverty and deprivation. Effects on relationships and their outcomes should be located within a 
more dynamic and contextualised approach as outlined above. It is also simplistic to demarcate the parenting practice of 'good' parents from that of 'bad' parents on the grounds of ability to improve or maintain quality couple relations (without a focus upon household income, familial characteristics, and environmental contexts). This can lead to the conclusion that the latter are unsuccessful because of personal failure to create stable/quality relationships and are therefore personally responsible for their poverty, cementing neo-liberal ideology and policy (Robson, 2010).

In our view, it is irrational to assume that simply because there is an intricate link between parenting and poverty that the solution is to encourage parents who find it hard to cope to emulate affluent ones, regardless of wider contexts. Relational aspects are important but taken alone offer a reductionist solution to the consequences of structural neighbourhood or community poverty. Current UK policy, which will see poor families most adversely affected by the reductions in welfare benefits (Brewer et al., 2013), will reduce the ability of families to cope, exacerbating stress, reducing resilience, and exerting more pressure on couple relations and ability to parent.

The automatic assumption that stable couple relationships will extend to better parenting practices and relations does not sufficiently fit the evidence. Policy makers need to examine more closely the complexity of existing empirical evidence. They need to heed the limitations identified in the knowledge base and put forward coherent initiatives which will meet the aim of giving children the best possible start in life, promote effective parenting, and prevent poverty. This means focusing upon financial and structural issues, as much as relational questions; and developing policies which address the material impact upon relationships in all its complex forms, objective and subjective. It also means contesting the current terrain of neo- 
liberal family ideology through recourse to the above evidence around complexity and dynamism and reframing policies and research. The emergence of a critical concept of 'wellbeing', particularly its dynamic and multifaceted nature (La Placa and Corlyon, 2014b; La Placa and Knight, 2014), might assist in provision of a new framework to locate research around parenting, life-chances and children's quality of life that contest current conceptualisations and assist in confronting increased economic and health inequalities. This would also emphasise the active and dynamic agency of families as they construct their lives and interpret their environments.

\section{Conclusion}

This article has reviewed the evidence around the relationship between parenting and poverty. The evidence suggests an intricate relationship between complex and mediating processes of income poverty, parental stress, disrupted parenting practices and neighbourhoods and environments, as opposed to a simplistic causal relationship between poverty, parenting, and child outcomes. It then proceeded to suggest responses to enhance the evidence base. Finally, it considered the implications of the evidence for child poverty policy, positing that current responses are too simplistic and do not sufficiently reflect the evidence base. 


\section{References}

About Families: Centre for Research on Families and Relationships (CRFR). (2012) Parenting on a low income: topic report, March 2012, Edinburgh: About Families.

Alakeson, V. (2012) The price of motherhood: women and part-time work, London: Resolution Foundation.

Alcock, P. (2006) Understanding poverty, 3rd edn., London: Palgrave.

Allen, G. (2011) Early intervention, the next steps: an independent report to Her Majesty's Government, London: HM Government.

Archer, L., DeWitt, J., Osborne, J., Dillon, J., Willis, B. and Wong, B. (2012) 'Science aspirations and family habitus: how families shape children's engagement and identification with science', American Educational Research Journal, 49, 5, 881-908.

Ashworth, K., Hardman, J., Liu, W. C., Maguire, S., Middleton, S., Dearden, L., Emmerson, C., Frayne, C., Goodman, A., Ichimura, H. and Meghir, C. (2001) Educational maintenance allowance, the first year: a quantitative evaluation, research report 257, London: DfES.

Asmussen, K., Corlyon, J., Hauari, H. and La Placa, V. (2007) Supporting parents of teenagers, research report 830, London: DfES.

Attree, P. (2005) 'Parenting support in the context of poverty: a meta-synthesis of the qualitative evidence', Health and Social Care in the Community, 13, 4, 330337.

Avis, M., Bulman, D. and Leighton, P. (2007) 'Factors affecting participation in Sure Start programmes: a qualitative investigation of parents' views', Health and Social Care in the Community, 15, 1, 203-211.

Axford, N., Lehtonen, M., Kaoukji, D., Tobin, K. and Berry, V. (2012) 'Engaging parents in parenting programs: lessons from research and practice', Children and Youth Services Review, 34, 10, 2061-2071. 
Barnes, J. (2004) Place and parenting, a study of four communities: the relevance of community characteristics and residents' perceptions of their neighbourhoods for parenting and child behaviour in four contrasting locations: final report of the families and neighbourhoods study (FANS) submitted to the NSPCC, part 1: quantitative results, London: Institute for the Study of Children, Families and Social Issues, Birkbeck, University of London.

Baumrind, D. (1991) 'The influence of parenting style on adolescent competence and substance misuse', Journal of Early Adolescence, 11, 1, 56-95.

Belsky, J. (1984) 'The determinants of parenting: a process model', Child Development, 55, 1, 56-95.

Belsky, J. and Vondra, I. (1989) 'Lessons from child abuse: the determinants of parenting', in D. Chicchetti and V. Carlson (eds.), Child maltreatment, Cambridge: Cambridge University Press, 153-202.

Berthoud, R., Bryan, M. and Bardasi, E. (2004) The dynamics of deprivation: the relationship between income and material deprivation over time, London: DWP.

Blanden, J. and Gregg, P. (2004) Family income and educational attainment: a review of approaches and evidence for Britain, London: Centre for Economic Performance, London School of Economics.

Borgonovi, F. and Montt, G. (2012) Parental involvement in selected PISA countries and economies, OECD educational working paper, number 73, Paris: OECD.

Boyden, J., Hardgrove, J. and Knowles, C. (2012) 'Continuity and change in poor children's lives: evidence from young lives', in A. Minujin and S. Nandy (eds.), Global child poverty and wellbeing: measurements, concepts, policy and action, Bristol: Policy Press, 475-507.

Bradbury, B. (2003) Child poverty: a review, policy research paper no. 2, Canberra: Commonwealth Department of Family and Community Services. 
Brewer, M., Browne, J., Hood, A., Joyce, R. and Sibieta, L. (2013) 'The short- and medium-term impacts of the recession on the UK income distribution', Fiscal Studies, 34, 2, 179-201.

Bronfenbrenner, U. (1989) 'Ecological systems theory', in R. Vasta (ed.), Annals of child development- six theories of child development: revised formulations and current issues, Greenwich, CT: JAI, 187- 250.

Caughy, M. O., O'Campo, P. J. and Mutaner, C. (2003) 'When being alone might be better: neighbourhood poverty, social capital and child mental health', Social Science and Medicine, 57, 2, 227-237.

Cawson, P., Wattam, C. Brooker, S. and Kelly, G. (2000) Child maltreatment in the United Kingdom: a study of the prevalence of child abuse and neglect, London: NSPCC.

Chen, Z. and Kaplan, H. (2001) 'Intergenerational transmission of constructive parenting', Journal of Marriage and the Family, 63, 17-31.

Conger, R. D., Patterson, G. R. and Ge, X. (1995) 'It takes two to replicate: a meditational model for the impact of parents' stress on adolescent adjustment', Child Development, 66, 1, 80-97.

Cooper, K. and Stewart, K. (2013) Does money affect children's outcomes? A systematic review, York: Joseph Rowntree Foundation.

Curtis, L., Dooley, M. and Phipps, S. (2004) 'Child well-being and neighbourhood quality: evidence from the Canadian National Longitudinal Survey of Children and Youth', Social Science and Medicine, 58, 10, 1917-1927.

Dahl, G. B. and Lochner, L. (2005) 'The impact of family income on child Achievement (working paper11279)', Cambridge, MA: National Bureau of Economic Research, http://www.nber.org/papers/w11279 [accessed 22.12.14].

Daly, M. (2011) 'Shifts in family policy in the UK under New Labour', Journal of European Social Policy, 20, 5, 433-443. 
Davis, F.A., McDonald, L. and Axford, N. (2012) Technique is not enough: a framework for ensuring that evidence-based parenting programmes are socially inclusive: discussion paper - August 2012, Leicester: British Psychological Society.

Desforges, C. and Abouchaar, A. (2003) The impact of parental involvement, parental support and family achievements and adjustment: a literature review, research report no. 433 , London. DfES.

Dyson, C., Gorin, S., Hooper, C. and Cabral, C. (2009) 'Bangladeshi families living in hardship: findings from research using a life-history approach', Child and Family Social Work, 14, 3, 362-371.

Edwards, R. and Gillies, V. (2004) 'Support in parenting: values and consensus concerning who to turn to', Journal of Social Policy, 33, 4, 627-647.

Elder, G., Van Nguyen, T. and Caspi, A. (1985) 'Linking family hardships to children's lives', Child Development, 56, 2, 361-375.

Epps, S. R. and Huston, A. C. (2007) 'Effects of a poverty intervention policy demonstration on parenting and child behaviour: a test of the direction of effects', Social Science Quarterly, 88, 2, 344-365.

Ermisch, J., Francesconi, M. and Pevalin, D. J. (2000) Outcomes for children of poverty: DWP Research report, no. 158, Leeds: HMO.

Fauth, R. C., Leventhal, T. and Brooks-Gunn, J. (2007) 'Welcome to the neighbourhood? Long-term impacts of moving to low-poverty neighborhoods on poor children's and adolescents' outcomes', Journal of Research on Adolescence, 17, 2, 249-284.

Feinstein, L. (2003) 'Inequality in the early cognitive development of British children in the 1970 cohort', Economica, 70, 73-79.

Feinstein, L., Duckworth, K. and Sabates, R. (2004) A model of the intergenerational transmission of educational success: wider benefits of learning, research report no. 10, London: Centre for Research on the Wider Benefits of Learning. 
Field, F. (2010) The foundation years: preventing poor children becoming poor adults: the report of the independent review on poverty and life chances, London: Cabinet Office.

Fram, M. S. (2003) Managing to parent: social support, social capital, and parenting practices among welfare-participating mothers with young children, Institute for Research on Poverty discussion paper no. 1263-03, Washington, D. C.: Institute for Research on Poverty.

Friedrichs, J., Galster, G. and Musterd, S. (2013) Life in poverty neighbourhoods: European and American perspectives, London: Routledge.

Furstenberg, Jr., F. F., Cooke, T. D., Eccles, J., Elder, G. H. and Sameroff, A. (1999) Managing to make it: urban families and adolescent success, Chicago: University of Chicago Press.

Gentleman, A. (2012) 'Housing benefit cap forces families to leave central London or be homeless', http://www.theguardian.com/society/2012/feb/16/housing-benefit-capfamilies-central-london [accessed 16.02.12].

Ghate, D. and Hazel, N. (2002) Parenting in poor environments: stress, support and coping, London: Jessica Kingsley.

Gibbs, G. R. (2007) Analyzing qualitative data, Sage: London.

Giddens, A. (1984) The constitution of society, Cambridge: Polity Press.

Gillies, V. (2005a) 'Raising the meritocracy: parenting and the individualization of social class', Sociology, 39, 5, 835-853.

Gillies, V. (2005b) 'Meeting parents' needs? Discourses of "support” and "inclusion" in family policy', Critical Social Policy, 25, 1, 70-90.

Gillies, V. (2007) Marginalised mothers: exploring working class experiences of parenting, Abingdon: Routledge. 
Gillies, V. (2008) 'Perspectives on parenting responsibility: contextualizing values and practices', Journal of Law and Society, 35, 1, 95-112.

Gillies, V. (2011) 'From function to competence: engaging with the new politics of family', Sociological Research Online, 16, http://www.socresonline.org.uk/16/4/11.html [accessed 22.12.14].

Gillies, V. (2013) 'Personalising poverty: parental determinism and the Big Society agenda', in W. Atkinson, S. Roberts and M. Savage (eds.), Class inequality in austerity Britain: power, difference and suffering, Basingstoke: Palgrave, 90111.

Gordon, D. (1998) 'Definitions of concepts for the perception of poverty and social exclusion’, in J. Bradshaw, D. Gordon, R. Levitas, S. Middleton, C. Pantazis, S. Payne and P. Townsend (eds.), Perceptions of poverty and social exclusion: report on preparatory research, Townsend Centre for International Poverty Research, Bristol: University of Bristol, 5-15.

Gordon, D. and Nandy, S. (2012) 'Measuring child poverty and deprivation', in A. Minuji and S. Nandy (eds.), Global child poverty and wellbeing: measurements, concepts, policy and action, Bristol: Policy Press, 57-103.

Gregg, P. and Washbrook, E. (2011) 'The role of attitudes and behaviours in explaining socio-economic differences in attainment at 11', Longitudinal and Life Course Studies, 2, 1, 41-58.

Gutman, L. M., McLoyd, V. C. and Tokoyawa, T. (2005) 'Financial strain, neighbourhood stress, parenting behaviours, and adolescent adjustment in urban African American families', Journal of Research on Adolescence, 15, $4,425-449$. 
Gutman, L. M., Brown, J. and Ackerman, R. (2009) Nurturing parenting capability: the early years, London: Center for Research on the Wider Benefits of Learning, Institute of Education.

Harris, K. and Marmer, J. (1996) 'Poverty, paternal involvement and adolescent wellbeing', Journal of Family Issues, 17, 5, 614-640.

Hartas, D. (2011) 'Families’ social background matter: socio-economic factors, home learning and young children's language, literacy and social outcomes', British Educational Research Journal, 37, 6, 893-914.

Hartas, D. (2012) 'Inequality and the home learning environment: predictions about seven-year-olds' language and literacy', British Educational Research Journal, 38, 5, 859-879.

Hartas, D. (2014) Parenting, family policy and children's well-being in an unequal society: a new culture war for parents, London: Palgrave.

Hill, A. and Spittlehouse, C. (2003) 'What is critical appraisal?', Evidence-Based Medicine, 3, 2, 1-8.

Hills, J., Brewer, M., Jenkins, S., Lister, R., Lupton, R., Machin, S., Mills, C., Madood, T., Rees, T. and Riddell, S. (2010) An anatomy of economic inequality in the UK: report of the National Equality Panel, London: Centre for Analysis of Social Exclusion.

Hobcraft, J. (1998) Intergenerational and life course transmission of social exclusion: influences of childhood poverty, family disruption, and contact with the police: CASE paper 15, London: London School of Economics, STICERD.

Holmes, J. and Kiernan, K. (2010) Fragile families in the UK: Evidence from the Millennium Cohort Study, York: Joseph Rowntree Foundation.

Holmes, J. and Kiernan, K. (2013) 'Persistent poverty and children's development in The early years of childhood', Policy and Politics, 41, 1, 19-41.

Jefferis, B., Power, C. and Hertzman, C. (2002) 'Birth weight, childhood socioeconomic environment and cognitive development in the 1958 British birth cohort study', British Medical Journal, 325, 305-308. 
Jencks, C. and Mayer, S. E. (1990) 'The social consequences of growing up in a poor neighbourhood', in L. Lynn and M. McGeary (eds.), Inner-city poverty in the United States, Washington D. C.: National Academy of Sciences Press, 111186.

Jensen, T. and Tyler, I. (2012) 'Austerity parenting: new economies of parentcitizenship', Studies in the Maternal, 4, 2, http://www.mamsie.bbk.ac.uk/editorial.html [accessed 22.12.14].

Katz, I., Corlyon, J., La Placa, V. and Hunter, S. (2007a) The relationship between parenting and poverty, London: Joseph Rowntree Foundation.

Katz, I., La Placa, V. and Hunter, S. (2007b). Barriers to inclusion and successful engagement of parents in mainstream services, York: Joseph Rowntree Foundation.

Kiernan, K. E. and Mensah, F. K. (2011) 'Poverty, family, resources and children's early educational attainment: the mediating role of parenting', British Educational Research Journal, 37, 2, 317-336.

Kumar, V. (1993) Poverty and inequality in the UK: the effects on children, London: Daycare Trust.

La Placa, V. and Corlyon, J. (2014a) 'Barriers to inclusion and successful engagement of parents in mainstream services: evidence and research', Journal of Children's Services, 9, 3, 220-234.

La Placa, V. and Corlyon, J. (2014b). 'Social tourism and organised capitalism: research, policy and practice'. Journal of Policy Research in Tourism, Leisure and Events, 6, 1, 66-79.

La Placa, V. and Knight, A. (2014). ‘Wellbeing: a new policy phenomenon?', in A. Knight, V. La Placa and A. McNaught (eds.), Wellbeing: policy and practice, Banbury: Lantern, 17-27. 
La Placa, V., McVey, D., MacGregor, E., Smith, A. and Scott, M. (2014) 'The contribution of qualitative research to the Healthy Foundations Life-stage Segmentation', Critical Public Health, 24, 3, 266-282.

Larzelere, R. E. and Patterson, G. R. (1990) 'Parental management: mediator of the effect of socioeconomic status on early delinquency', Criminology, 28, 2, 307-323.

Leventhal, T. and Brooks-Gunn, J. (2003) 'Moving to opportunity: an experimental study of neighborhood effects on mental health', American Journal of Public Health, 93, 9, 1576-1582.

Levitas, R. (2012) 'Utopia calling: eradicating child poverty in the United Kingdom and beyond', in A. Minujin and S. Nandy (eds.), Global child poverty and wellbeing: measurements, concepts, policy and action, Bristol: Policy Press, 449-475.

Lexmond, J. and Reeves, R. (2009) Parents are the principal architects of a fairer society: building character, London: Demos.

Lindblad-Goldberg, M. (1989) ‘Successful minority single-parent families' in L. Combrink-Graham (ed.), Children in family contexts, New York: Guildford Press, 116-134.

Lister, R. (2010) Understanding theories and concepts in social policy, Bristol: Policy Press.

Lundberg, S., Pollack, R. and Wales, T. (1997) 'Do husbands and wives pool their resources?', Journal of Human Resources, 32, 463-480.

Marsh, A. and McKay, S. (1994) Poor smokers, London: Policy Studies Institute.

Mayer, S. E. (1997) What money can't buy, Cambridge, MA: Harvard University Press.

McCulloch, A. and Joshi, H. E. (2001) 'Neighbourhood and family influences on the cognitive ability of children in the British National Child Development Study', Social Science and Medicine, 53, 5, 579-591. 
McDonald, L., FitzRoy, S., Fuchs, I., Fooken, I. and Klasen, H. (2012) 'Strategies for high retention rates of low-income families in FAST (families and schools together): an evidence-based parenting programme in the USA, UK, Holland and Germany', European Journal of Developmental Psychology, 9, 1, 75-88.

McSherry, D. (2004) 'Which came first, the chicken or the egg? Examining the relationship between child neglect and poverty', British Journal of Social Work, 34, 5, 727-733.

Meltzer, H., Gatward, R., Goodman, R. and Ford, T. (2000) Mental health of children and adolescents in Great Britain, London: The Stationery Office.

Middleton, S., Ashworth, K. and Braithwaite, I. (1997) Small fortunes: spending on children, childhood poverty and parental sacrifice, York: Joseph Rowntree Foundation.

Moore, K. A and Vandivere, S. (2000) Stressful family lives: child and parent wellbeing: child trends, Series B-17, Washington D. C.: The Urban Institute.

Moran, P., Ghate, D. and van der Merwe, A. (2004) What works in parenting support? A review of the international evidence, DfES: London.

Moulin, S. Waldfogel, J. and Washbrook, E. (2014) Baby bonds: parenting, attachment and a secure base for children, London: The Sutton Trust.

Newland, R. P., Crnic, K. A., Cox, M. J. and Mills-Koonce, R. (2013) 'The family model stress and maternal psychological symptoms: mediated pathways from economic hardship to parenting', Journal of Family Psychology, 27, 1, 96105.

Oakley, A., Hickey, D. and Rigby, A. S. (1994) 'Love or money? Social support, class inequality and the health of women and children', European Journal of Public Health, 4, 4, 265-273.

O’Connor, T. and Scott, S. (2007) Parenting and outcomes for children, York: Joseph Rowntree Foundation.

O’Neill, R. (2002) Experiments in living: the fatherless family, London: CIVITAS. 
Otter, C. (2013) 'Family resources and mid-life level of education: a longitudinal study of the mediating influence of childhood parental involvement', British Educational Research Journal, 40, 3, 555-574.

Park, S. and Holloway, S. (2013) 'No parent left behind: predicting parental involvement in adolescents' education within a sociodemographically diverse population', The Journal of Educational Research, 106, 2, 105-119.

Parke, R. and Buriel, R. (1998) 'Socialisation in the family: ecological and ethical perspectives', in N. Eisenberg, W. Damon and R. M. Lerner (eds.), Handbook of child psychology: social, emotional, and personality development, $5^{\text {th }}$ edn., New York: Wiley, 429-505.

Peters, M., Seeds, K., Goldstein, A. and Coleman, N. (2008) Parental involvement in children's education 2007: research report DCSF-RR034, London: BMRB Research/DCSF.

Pheonix, A. and Husain, F. (2007) Parenting and ethnicity, York: Joseph Rowntree Foundation.

Pinderhughes, E. E., Nix, R., Foster, E. M. and Jones, D. (2001) 'Parenting in context: impact of neighbourhood poverty, residential stability, public services, social networks, and danger on parental behaviours, Journal of Family and Marriage, 63, 941-953.

Popay, J. and Mallinson, S. (2013) 'Qualitative research review and synthesis', in I. Bourgeault, R. Dingwall, and R. de Vries. (eds.), The sage handbook of qualitative research methods in health research, Sage: London, 289-307.

Reay, D. (2013) 'Social mobility, a panacea for austere times; tales of emperors, frogs, and tadpoles', British Journal of Sociology of Education, 34, 5-6, 660677.

Ridge, T. (2009) Living with poverty: a review of the literature on children's and families' experiences of poverty, research report No 594, London: DWP.

Rigg, J. and Sefton, T. (2004) Income dynamics and the life cycle, CASE paper 24, London: London School of Economics. 
Robson, K. (2010) 'Good responsible parenting: child-support guidelines in an era of neo-liberalism', Canadian Journal of Law and Society, 25, 2, 129-148.

Ross, D. P. and Roberts, P. (1999) Income and child well-being: a new perspective on the poverty debate, Ottawa: Canadian Council on Social Development.

Russell, M., Harris, B. and Gockel, A. (2008) 'Parenting in poverty: perspectives of high-risk parents', Journal of Children and Poverty, 14, 1, 83-98.

Sanbonmatsu, L., Kling, J. R., Duncan, G. J. and Brooks-Gunn, J. (2006)

Neighborhoods and academic achievement: results from the moving to opportunity experiment: NBER working paper no. 11909, Cambridge, MA: National Bureau of Economic Research.

Sastry, N. (2015) 'Stressful life experiences and contexts: the effects on parents and parenting', in P. R. Amato, A. Booth, S. M. McHale and J. Van Hook (eds.), Families in an era of increasing inequalities: diverging destinies, London: Springer, 105-115.

Siraj-Blatchford, I. (2010) 'Learning in the home and at school: how working class children "succeed against the odds", British Educational Research Journal, $36,6,463-482$.

Smith, N. and Middleton, S. (2007) A review of poverty dynamics research in the UK, York: Joseph Rowntree Foundation.

Spencer, M. (1996) Poverty and child health, Oxford: Radcliffe Medical Press.

Sullivan, A. Joshi, H., Ketende, S. and Obolenskaya, P. (2010) The consequences at age 7 of early childhood disadvantage in Northern Ireland and Great Britain, London: Institute of Education.

Tavistock Institute of Human Relations, National Foundation for Educational Research, Thomas Corum Research Unit and Qa Research. (2014) Relationship support interventions evaluation, research report $R R 315$, Department of Education: London. 
Turner, H. (2006) 'Stress, social resources, and depression among never-married and divorced rural mothers', Rural Sociology, 71, 3, 479-504.

Van Ham, M., Hedman, L., Manley, D., Coulter, R. and Osth, J. (2014)

'Intergenerational transmission of neighbourhood poverty: an analysis of neighbourhood histories of individuals', Transactions of the Institute of British Geographers, 39, 3, 402-417.

Waylen, A. and Stewart-Brown, S. (2009) 'Factors influencing parenting in early childhood: a prospective longitudinal study focusing on change', Child: Care, Health and Development, 36, 2, 198-207.

Welshman, J. (2007) From transmitted deprivation to social exclusion: policy, poverty, and parenting, Bristol: Policy Press.

Yaqub, S. (2002) 'Poor children grow into poor adults: harmful mechanism or overdeterministic theory?', Journal of International Development, 14, 8, 10811093. 